\title{
Determination and Evaluation of the Rate of Solid Wastes Generation in Health Care Centers in Montevideo, Uruguay
}

\author{
Lady Carolina Ramírez*, Alice Elizabeth González, Nicolás Rezzano Tizze \\ Department of Environmental Engineering, Institute of Fluid Mechanics and Environmental Engineering, \\ School of Engineering of Engineering, Universidad de la República, Montevideo, Uruguay \\ Email: *crgarcia@fing.edu.uy
}

How to cite this paper: Ramírez, L.C., González, A.E. and Tizze, N.R. (2017) Determination and Evaluation of the Rate of Solid Wastes Generation in Health Care Centers in Montevideo, Uruguay. International Journal of Clinical Medicine, 8, 652-667.

https://doi.org/10.4236/ijcm.2017.812061

Received: October 23, 2017

Accepted: December 24, 2017

Published: December 27, 2017

Copyright $\odot 2017$ by authors and Scientific Research Publishing Inc. This work is licensed under the Creative Commons Attribution International License (CC BY 4.0).

http://creativecommons.org/licenses/by/4.0/

(c) $\underset{\mathrm{EY}}{\mathrm{C}}$ Open Access

\begin{abstract}
Decree 586/009 establishes the main guidelines related to the management of Health Care Wastes (RAS). For this reason, it is used as a reference in the definition of any methodological proposal that intends to address all the aspects related to Intra-institutional Management of Residues generated in Health Care Centers (CAS) in Uruguay. In the first instance, this paper presents an application case based on the experience of previous work in a CAS in Montevideo. Providing special importance to the Evaluation of rates of sanitary waste removal rates in the hospital centers, which were determined based on historical data for the period from 2008 to 2011, referring to rates of removal of contaminated, common and recyclable sanitary waste. Based on the analysis of these data, information on their behavior is obtained, such as: number of common waste removed per day in the period, evolution of the monthly average of the daily rate of removal of common waste, evolution of the average daily waste removal rate from month to month in the period, average daily waste removal rate for each month of the year in the period considered, average daily rate of common waste removal for each day of the week, evolution of the monthly average of the daily rate of removal of contaminated waste, evolution of the monthly average daily withdrawal rate of contaminated waste in the period and mean of the daily rate of removal of contaminated waste for each month of the year in the period considered. Finally, the conclusions of this article present the procedure to perform a weighing campaign, which should be carried out to determine the common and contaminated waste generation rates in each of the main services of the CAS.
\end{abstract}

\section{Keywords}

Rate of Solid Waste Generation, Common Wastes, Contaminated Wastes 


\section{Introduction}

The definition of Health Care Wastes (RAS), can vary significantly among countries in the European Union, RAS are the wastes of chapter 18 of the European Waste Catalogue [1] which are defined as the wastes from human or animal health-care and/or related research. The World Health Organization (WHO) designates RAS as the wastes generated by health-care activities that can include a wide range of materials, such as used needles and syringes, soiled dressings, body parts, diagnostic samples, blood, chemicals, pharmaceuticals, medical devices and radioactive materials. Variable definitions of RAS exist in other parts of the world too [2]. In addition, it is not often clear whether household type wastes (non-hazardous wastes) are also included in the RAS. For example, in Jordan, [3] grouped RAS into: 1) pathological waste, 2) sharps and 3) infectious wastes. In Uruguay, the issue of RAS began to be studied with the enactment of Decree 135/99 in 1999, which would be repealed ten years later by Decree 586/009 [4]. This decree establishes the guidelines that should be taken into account both for the study and the management of RAS. According to the provisions of the Official Journal, Decree No. 586/009; Regarding the regulatory rules for the management of hospital waste, RAS are "solid, semi-solid, liquid or gaseous substances, materials or byproducts generated at Health Care Centers or Services, which are found contents in a container of which the generator, is detached or has the intention or obligation to discard. As Centers Health Care's hospitals, nursing homes, clinics, clinical laboratories, offices in general, medical centers, maternity hospitals, first aid rooms and any setting where any level of care is practiced understood human resources for prevention, diagnosis, treatment and rehabilitation, and health research centers" [5]. The services offered at the Health Care Centers are aimed at addressing and reducing health problems and to prevent potential risks to the health of the population. Achieving these services, however, inevitably it leads to generate waste that can be harmful to health [6].

Health Care waste-generation assessment is an important first step in the continuing improvement of hospital medical waste management. The results could be used to establish a baseline for planning, budgeting, cost controlling, and optimizing waste-management systems [7].

The proper classification of the waste generated in a Health Care Center allows its management to be efficient, economic and safe. Segregation facilitates proper classification of waste, reducing health risks and costs in handling them, as the safest and most expensive systems will be used only for the fraction of waste that has need of it and not for everyone.

In order to facilitate the collection of waste in the generation sources and taking into account the diversity of Health Care Centers, different classifications are established based on criteria such as type of source, type of risk, destination end of the waste, among others.

Taking this information as a criterion the health risk and considering the 
points of generation and types of treatment or disposal that should be given to waste, they are classified as hazardous and nonhazardous [8].

The amount of waste that is generated in a Health Care Center (hereinafter referred to as CAS) is a function of the various activities that are developed in it and will depend, among other factors, the number of medical services offered in the establishment, the degree of complexity of the care provided, the size of the Health Care Center, the proportion of outpatients attended and staffing. Therefore it is not easy to establish simple relationships to estimate the amount of waste Health Care based on such a variety of factors. This has led, in most cases, to relate the average amount of solid waste generated daily to the number of beds in the CAS, thus obtaining figures that, although subject to a certain degree of inaccuracy, are easier handling and application.

Latin American countries have shown a growing interest in the subject, which has resulted in several studies aimed at knowing the rate of solid waste generation in the CAS, as well as carrying out diagnostics of the situation of waste management. The comparative analysis of the results obtained in these studies should be made taking into account that the methodologies used in each case, and even the basic definitions adopted regarding Health Care Waste, were different.

Between $75 \%$ and $90 \%$ of Health Care Waste corresponds to waste assimilable to urban solid waste and $10 \%$ to $25 \%$ present some type of danger; within these less than $10 \%$ are infectious. This, considering that the percentage of infectious ones can be greater in the cases in which there is not a correct segregation. In the United States, this fraction varies from 5\% to $1 \%$ [9].

In developing countries, as is the case in most Latin American countries, estimates are still being handled; for this reason, the generation data presented in the studies that have been carried out are taken as examples and not as a basis for waste management in a Health Care Center. Even a narrow survey would provide more reliable data on local waste generation than any estimates based on data from other countries.

Table 1 shows that the average number of solid waste generation in hospitals in Latin America obtained fluctuates between $1.0 \mathrm{~kg}$ and $4.5 \mathrm{~kg} / \mathrm{bed} / \mathrm{day}$, and it can be seen that this generation rate tends to increase over time. This behavior coincides with the evolution shown by the rate of generation of health care waste in developed countries; although in these latter countries the current rates of waste generation are significantly higher than those in developing countries. The main causes of this progressive increase in the rate of generation of Health Care Waste are the continuous increase in the complexity of medical care and the increasing use of disposable material.

In selected countries within Latin America and the Caribbean, the amounts of contaminated Health Care Waste produced in several health care facilities were estimated. Table 2 shows that these estimates are based on a value of 0.22 tons per year generated by each bed of health establishment; this value was proposed 
Table 1. RAS generation rate in some Latin American countries.

\begin{tabular}{ccccc}
\hline \multirow{2}{*}{ Rate of Solid Waste Generation of hospitals in Some Latin-American Countries } \\
\hline \multirow{2}{*}{ Country } & Year of Study & \multicolumn{3}{c}{ Generation (kg/bed/day) } \\
\cline { 3 - 5 } & 1973 & 0.97 & - & 1.21 \\
CHILE & 1976 & 2.56 & 3.1 & 3.71 \\
VENEZUELA & 1978 & 1.2 & 2.63 & 3.8 \\
BRASIL & 1982 & 0.82 & - & 4.2 \\
ARGENTINA & 1987 & 1.6 & 2.93 & 6 \\
PERÚ & 1988 & 1.85 & - & 3.65 \\
ARGENTINA & 1989 & 3 & 3.8 & 4.5 \\
URUGUAY & & 389 & Minimun \\
\hline
\end{tabular}

Source: Information provided, personnel department of environmental health of a CAS of the city of Montevideo [10].

Table 2. Quantities of risk factors produced in health care facilities in selected countries of Latin America and the Caribbean.

\begin{tabular}{ccc}
\hline COUNTRY & NUMBER OF BEDS & TONS OF DANGEROUS WASTE POR YEAR \\
\hline ARGENTINA & 150.000 & 32.850 \\
BRASIL & 501.660 & 109.960 \\
CUBA & 50.293 & 11.010 \\
JAMAICA & 5.745 & 1.260 \\
MEXICO & 60.100 & 131.160 \\
VENEZUELA & 47.200 & 10.340 \\
\hline
\end{tabular}

Source: Koning et al., 1994, quoted by (Pruess et al., 1998) [6].

by Koning in 1994 quoted by [6].

The priority of the Health Care Centers (CAS) is patient care and, consequently, its policy has traditionally been oriented towards the benefit of the patient's health and well-being, which has diminished the importance of environmental problems. However, it is essential that within the objectives of the CAS, environmental protection is present because otherwise you can create a vicious cycle of diseases resulting from improper handling of waste, which affects the personnel in charge of this work, the community of the CAS and the population. For this reason, it is essential that the people responsible for conducting a CAS are aware of the need to adopt an environmental policy that considers the impacts and consequences of waste management. The management of Health Care Waste presents potential risks to the Health and Safety of those who work in the Health Care Centers and for the population in general. This has been the main motivation in Uruguay to start studying and working in the management of Health Care Waste.

The scarcity of environmental statistics series is noticeable in Latin American 
countries, and the situation of countries is heterogeneous, both in terms of the capacity to produce statistics and the quality of the resulting information. In order to progressively overcome this situation and to advance as a region towards the production and harmonization of environmental statistics, it is necessary to consolidate institutions and develop national technical capacities. Currently in Latin America there has been an affirmed growth of interest with respect to the management of Health Care Waste, which has triggered the realization of several studies to discover the rate of solid waste generation in the CAS, as well as the performance of diagnoses of the situation of the waste management. However comparative analysis of the results of these studies should take into account that the methodologies used in each case, and even basic definitions adopted in respect of waste Health Care, were different. In the specific case of the city of Montevideo, there are currently no systematic studies concerning the Management of Health Care Residues (conducting diagnoses of the situation of Health Care Waste management or determining the rates of generation of Health Care Waste), which means that the known generation rates correspond to bibliographic data, of which most of the time there is no clear information on how they were obtained. For this reason, in this study, we sought to determine local sanitary waste removal rates to generate data more representative of the national situation, and even more, that could be useful as a reference for other Latin-American countries to set up their own protocols.

\section{Experience-Methodology}

Based on one of the projects related to the management of Health Care Waste that the Department of Environmental Engineering (DIA) of the Institute of Fluid Mechanics and Environmental Engineering (IMFIA) of the Faculty of Engineering (UdelaR) has come developed in the last years in some Centers of Health Care of the city of Montevideo and whose general objective has been the improvement of the inter-institutional management of said residues [11]. The system of inter-institutional waste management of a CAS in Montevideo was analyzed, managing a detailed diagnosis of this management system and implementing modifications, which resulted in improvements in management. The CAS in which the study was performed is a third level hospital for acute care for adults, which has an outsourced cleaning service. The staff of this company carries out the collection and transport of waste within the CAS and has the responsibility to provide the waste bags that are used.

At present the CAS manages its waste so that those assimilable to urban waste are removed and transported by a private company to the municipal final disposal site located at Felipe Cardozo Rd. and the contaminated waste is transferred, received, treated and arranged by another private company [12]. Established the following specific objectives that were intended to be achieved with the analysis of the management system of Health Care Waste:

Having a detailed diagnosis of waste management in the CAS. 
- Generate management protocols for the purpose of improving and formalizing waste management procedures in their different stages.

- Implement the protocols proposed in the CAS, resorting to conducting a training program selected building staff how to provide the actors in the knowledge needed for this.

\subsection{Diagnosis of the Initial Situation}

In order to make a diagnosis in relation to waste management as it was being carried out in the CAS, the location of the waste containers, capacity, type of containers and bags used in each case should be one of the collection rooms, methods and practices, internal transportation circuits, characteristics and location of transitional and final storage areas in the different sectors. Based on this information, which includes the types of RAS that are generated and the characteristics of the bags and containers used in the different areas of the CAS, maps of the initial situation were drawn up in which they are clearly and the results of the diagnosis can be easily understood, especially with regard to the characteristics and location of containers for solid wastes and intermediate deposits, as well as the circulation circuits of the different types of waste [13].

\subsection{Evaluation of Rates of Sanitary Waste Removal Rates in the Hospital Centers}

We worked with historical data for the period from 2008 to 2011, referring to rates of removal of contaminated, common and recyclable sanitary waste. These were provided by the staff of the Department of Hygiene and Cleaning of the CAS. The data that are available are daily removal of contaminated and common waste, and monthly data on the disposal of recyclable waste. Contaminated waste data are quantified in pots; the common and recyclable, in kilograms.

The characteristics of the available data have led to the need to work with retirement rates, although it is usual to work with waste generation rates. This decision is based on avoiding the introduction of factors of uncertainty or error in relation to the need to consider hypotheses to relate the quantities of waste collected and generated [14].

\section{Results and Discussion}

\subsection{Common Wastes}

It is observed that the daily withdrawal rate varies between a minimum of 200 $\mathrm{kg} /$ day and a maximum of $2480 \mathrm{~kg} /$ day. It should be mentioned that this absolute maximum of the data series corresponds to a Monday in which there was no collection on the previous Saturday, because it was a holiday (that is, in that value, besides the generation of the weekend, between 8:00 a.m. and Saturday at 8:00 p.m., with previous averages expected to be $2244 \mathrm{~kg}$ of common waste, but it is quite possible that in view of the imminence of the "long weekend", the activity on Thursday had been overloaded The second maximum (2440 kg/day) 
corresponds to a Friday in which there was no collection on the previous Thursday (this implies that the wastes that are removed are those generated between Wednesday at 8:00 p.m and on Friday at 8:00 a.m, since Thursday was not a holiday, but the collection of common solid waste was not collected, the expected amount to withdraw would have been, considering the previous averages, of $1898 \mathrm{~kg}$, here the diversion in relationship to the expected value is higher, but if on Friday the collection had been made rather close to noon, then incorporating the generation of the morning shift, which is the greater of the day, the deviation would result from the same order as in the previous case).

Figure 1 shows the daily averages of waste removal between September 2008 and January 2011. The data for 2008 is taken from the month of September since it is the month in which there starts to present a smaller amount of daily data missing. The waste weighing began to be carried out in February 2008. In May 2008 no retirement data was available, and in the months of February, March and April of the same year, the data had an irregular behavior and anomalous in relation to the later historical series, because the records were just beginning. On the other hand, in June and July there are 9 data missing from each month, in August 5, September 4 and October 2 are missing. The first month without missing data is December 2008.

In bars the data handled by the CAS is shown, and the red line represents the averages obtained by dividing the non-zero quantitative data by the number of days with data. That value would correspond to the average daily withdrawal in a week of six days, from Monday to Saturday, a value that has a historical average

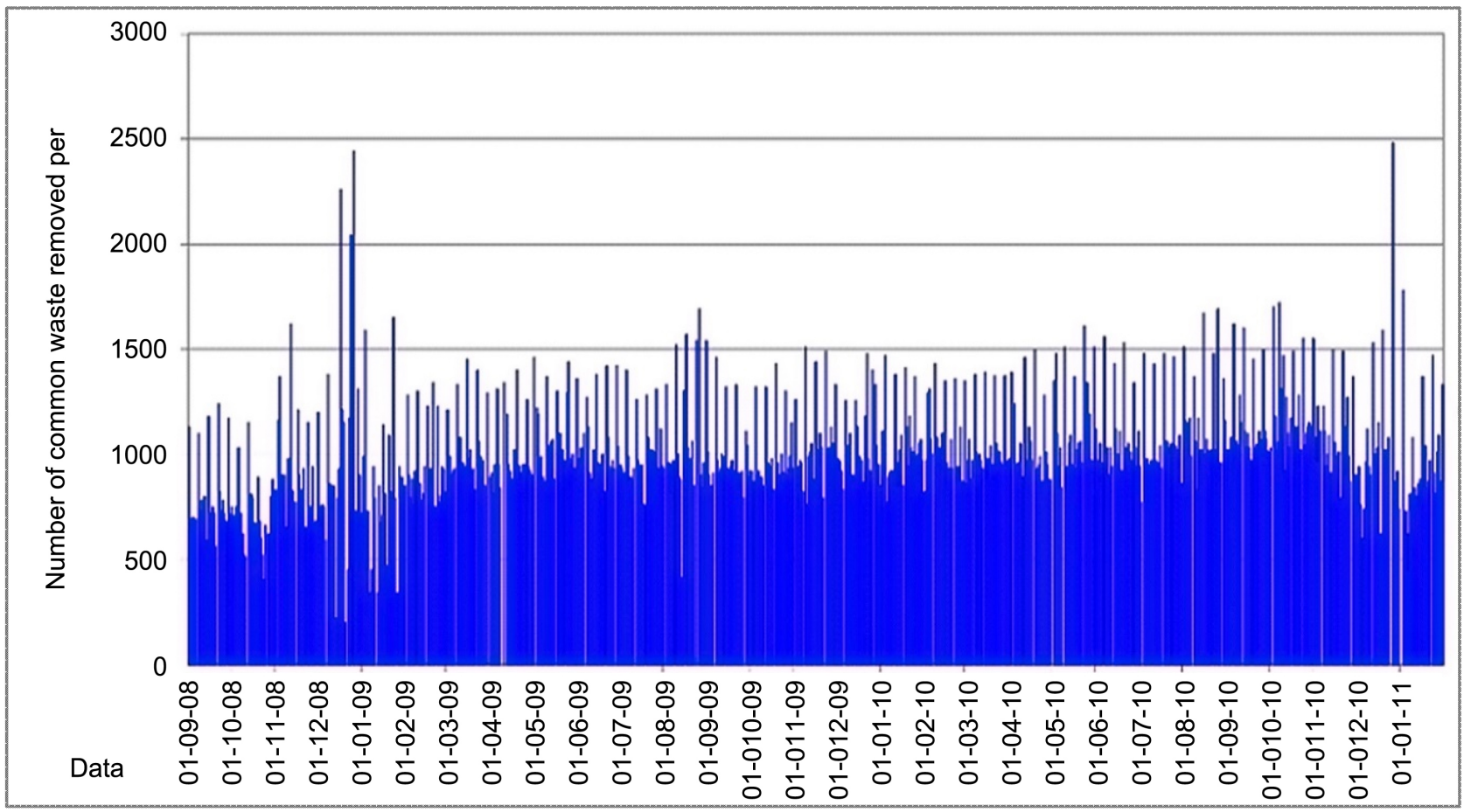

Figure 1. Number of common waste removed per day in the period September 2008 - January 2011 (kg/day). 
of $1012 \mathrm{~kg} /$ day.

There is an increasing tendency in the generation of common waste in the different months as time progresses. This trend was related to the improvement in the segregation at its source and was achieved through improvements in management, due to the fact that during the period corresponding to the data collection there were no significant investments in the increase in infrastructure or incorporation of new services, since the CAS has maintained approximately the same number of beds. An important aspect to be taken into account is that in a certain period, disposable food trays were used, which is supposed to have contributed to the increase in waste generation. It was not possible to specify the months in which this practice was carried out.

Figure 2 and Figure 3 present the monthly averages of the daily rate of common waste removal between September 2008 and January 2011.

Figure 4 presents the average generation rate, which is similar for the different months, with the minimum corresponding to January and the maximum to June.

When observing the variation of the waste removal for each day of the week, the theorical average daily that results of considering the weekly withdrawal evenly distributed in the 7 days of the week turns out to be $866 \mathrm{~kg} / \mathrm{day}$; if only the 6 days in which common waste is effectively removed, the average results to be $1012 \mathrm{~kg} /$ day. The graph of Figure 5 shows the average withdrawal rate for

Evolution of the monthly average of the daily rate of removel of common waste

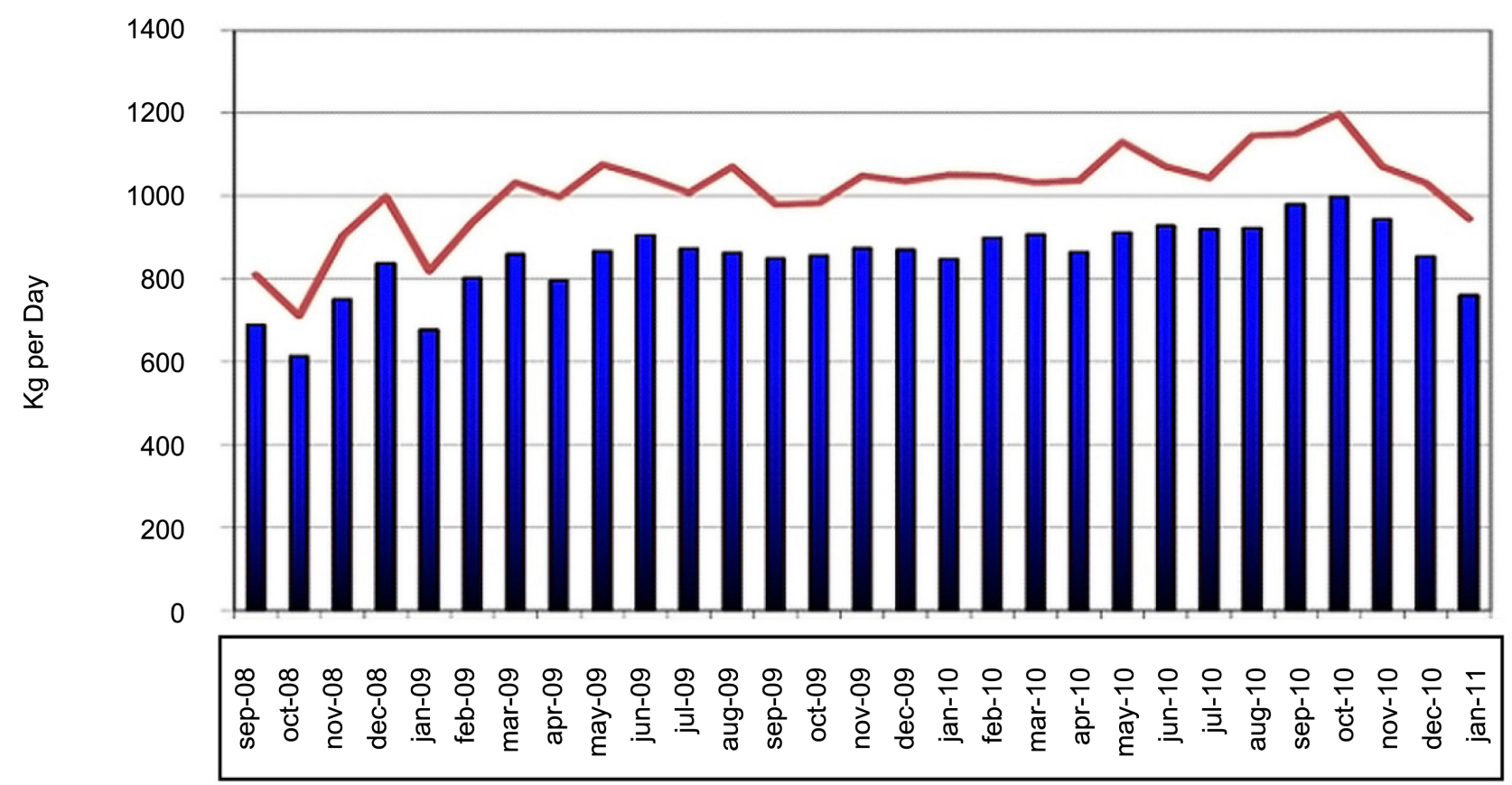

Months

Figure 2. Evolution of the monthly average of the daily rate of removal of common waste (kg/day) (red line: average over days with data). 


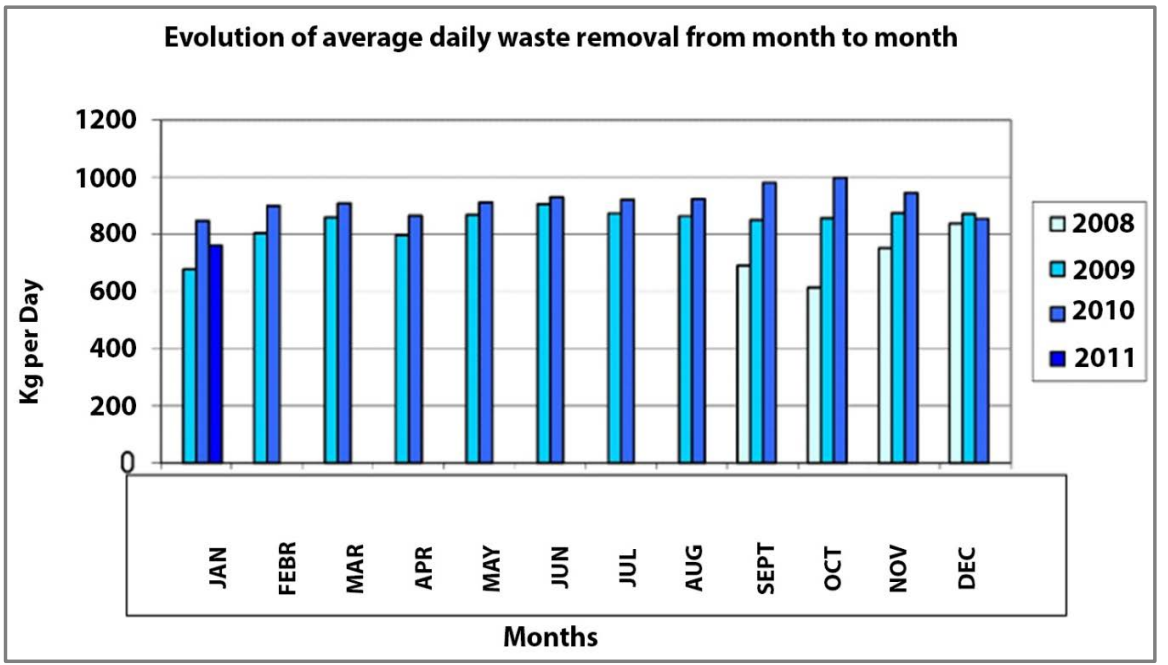

Figure 3. Evolution of the average daily waste removal rate from month to month, in the period from September 2008 to January 2011 (kg/day).

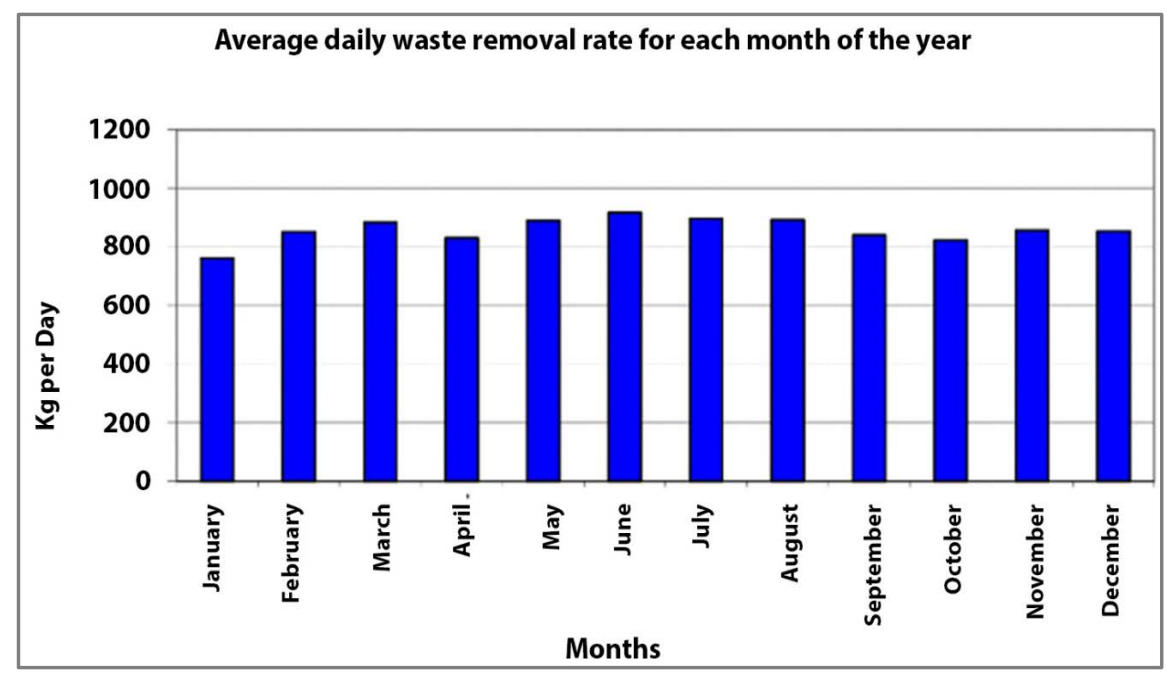

Figure 4. Average daily waste removal rate for each month of the year in the period considered (kg/day).

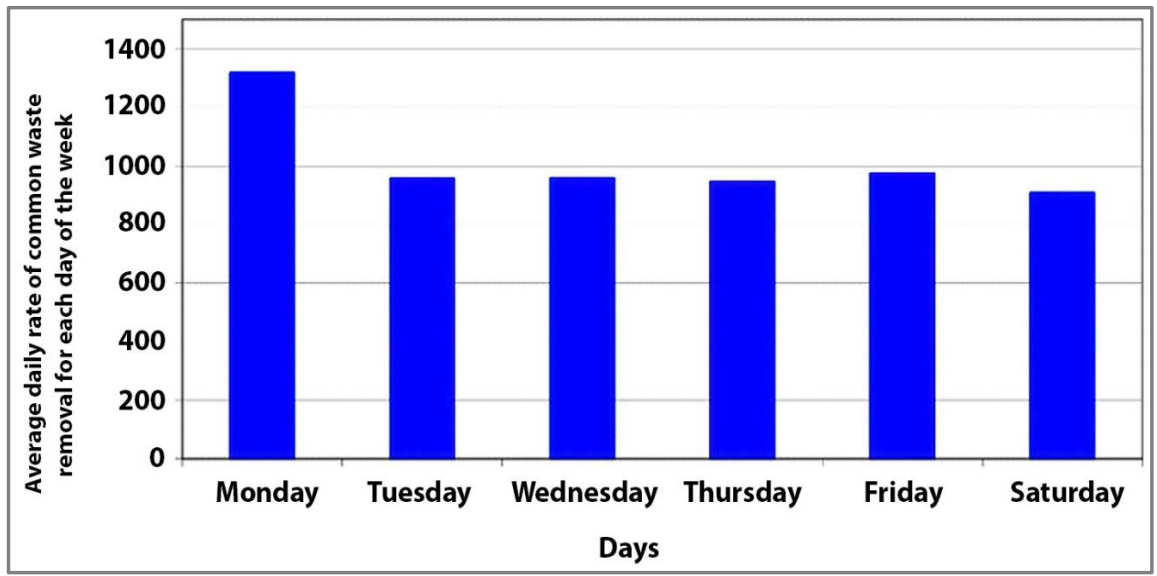

Figure 5. Average daily rate of common waste removal for each day of the week (kg/day). 
each day of the week.

As the company responsible for the removal of common waste carries out the withdrawal at 8:00 a.m, it should be considered that the withdrawal data corresponding to each day are related to the generation from the day before at 8:00 a.m to the moment of collection (for example, the retirement data for Thursday must be associated with the generation between 8:00 a.m on Wednesday and 8:00 a.m on Thursday).

On Sundays there is no removal of common waste, so the Monday recall includes the waste generated from Saturday at 8:00 a.m. to Monday at 8:00 a.m.

The daily withdrawal rate, that is, the generation from Monday to Friday is relatively constant between Tuesdays and Saturdays, with an average value of $949 \mathrm{~kg} /$ day. On Mondays the withdrawal is approximately $1320 \mathrm{~kg}$, corresponding to the waste generated during practically the entire weekend. However, since this value includes the generation corresponding to 2 days, for each of them a daily value would be much lower than that of the other days of the week. This is because on Saturdays and Sundays the administrative area does not work and some areas of assistance only work a few hours.

\subsection{Contaminated Waste}

Figure 6 shows the available information regarding the number of pots withdrawn day by day throughout the period. It is observed that the number of pots withdrawn per day varies between a minimum of 8 pots and a maximum of

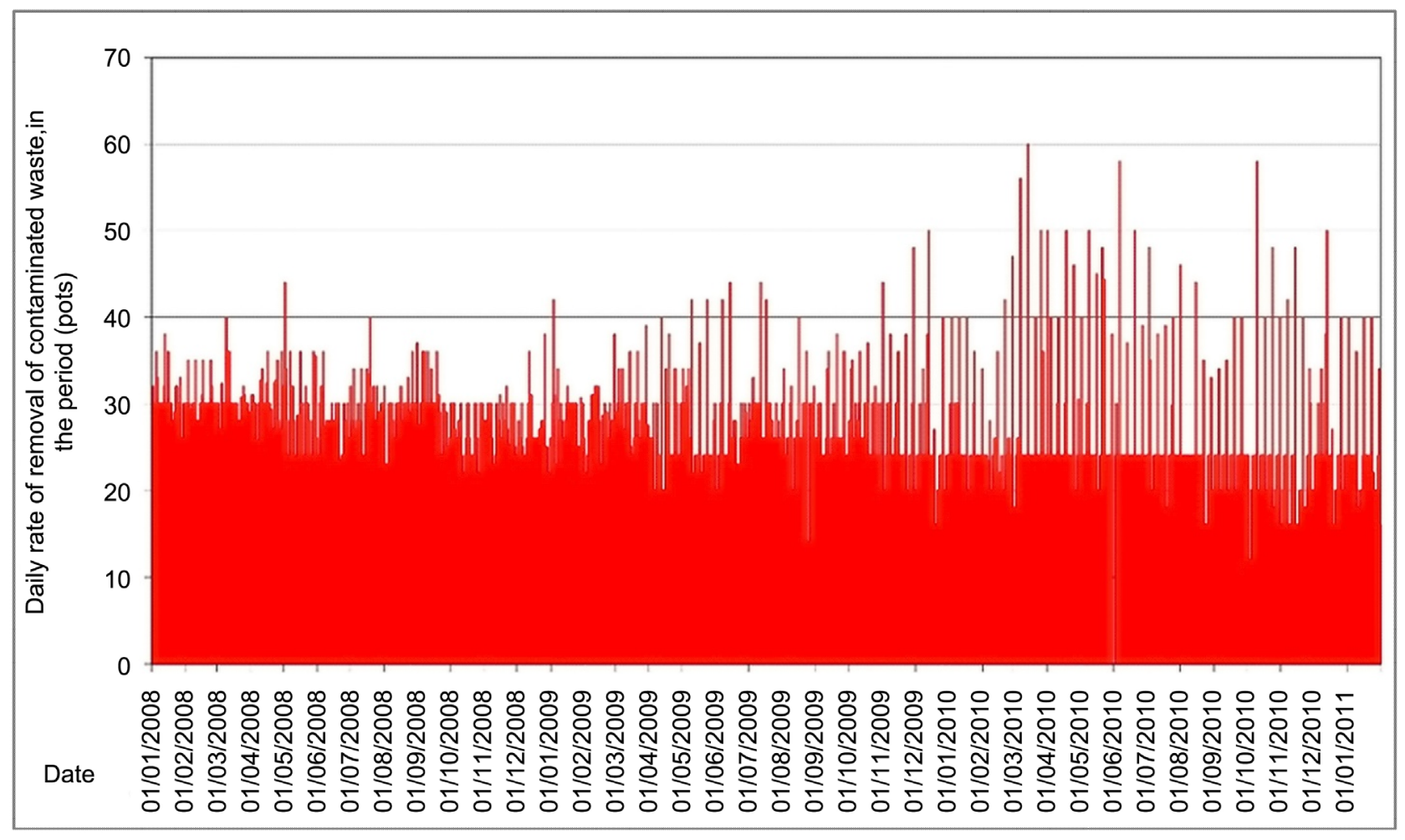

Figure 6. Daily rate of removal of contaminated waste, in the period January 2008 - January 2011 (pots/day). 
60 pots, with an average of 27 pots.

Figure 7 graphs the evolution of the monthly average of the daily rate of removal of contaminated waste:

Retrieval rates remain relatively constant in 2008, ranging from 25 to 30 pots per day, with an average of 28 pots per day. With respect to 2009 , the monthly average daily withdrawal rate of contaminated waste was 27 per day, slightly lower than that of 2008. The withdrawal rates remain relatively constant also in 2009, varying between 26 and 28 pots/day. In 2010, the monthly average daily withdrawal rate of contaminated waste continued to fall: it was 25 pots per day, varying in turn between 22 and 27 pots per day. Finally in 2011 only the data of the withdrawal rate corresponding to January, which results from 23 pots per day, is available.

The average retrieval rates for the years 2008, 2009 and 2010 were, therefore, 28,27 and 25 pots per day respectively. The decrease in the average daily rate of removal of contaminated waste for the year 2010 is two pots below the value corresponding to the year 2009 and three pots below the rate of the year 2008, which, taking the pot as a unit, implies that it has been possible to reduce the average daily generation in more than three pots from the moment that began to work on this issue in the CAS.

The evolution of the daily waste removal rate, month by month throughout the period under consideration, the average value for each month of the year is observed in Figure 8. When comparing the same month of each year, the trend

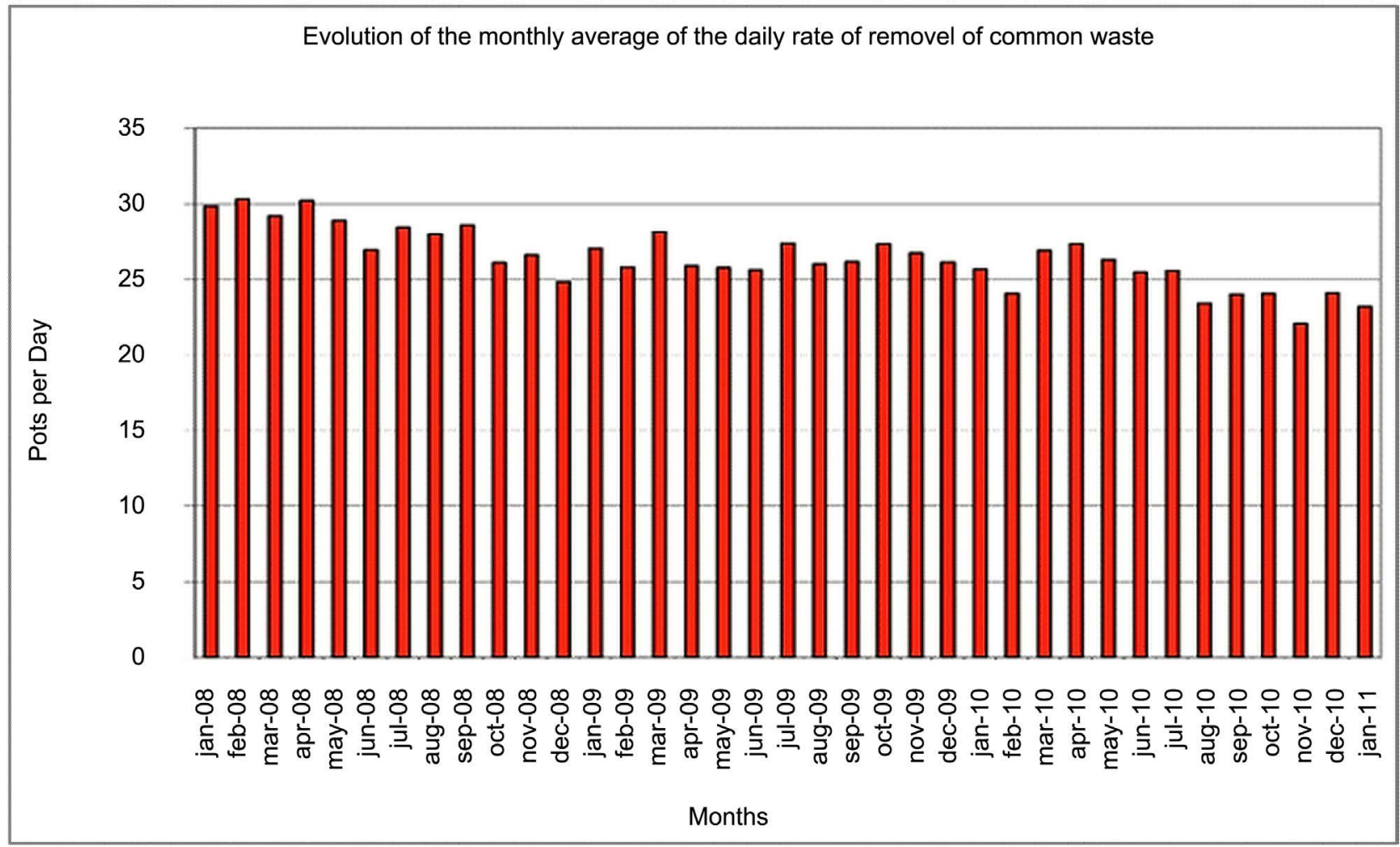

Figure 7. Evolution of the monthly average of the daily rate of removal of contaminated waste (pots/day). 
is generally decreasing, reducing the quantities of pots withdrawn.

Figure 9 shows the daily removal rates of contaminated waste for each day of the week, obtained from the total data. The removal of the contaminated waste is carried out at 00:30 by the company in charge of this task, so the waste collection data correspond to the generation of the previous day (by way of example, Thursday's value corresponds to the generation of the day Wednesday, between the 0:00 and the 24:00).

Withdrawal rates from Tuesday to Saturday remain relatively constant, at around 27 pots per day. However, on Mondays there is a significantly lower rate (its average value is around 21 pots per day) and Sunday has a significantly higher rate of 34 pots per day. The reason the withdrawal rate on Monday is lower than the average of the week is due to the lower generation of

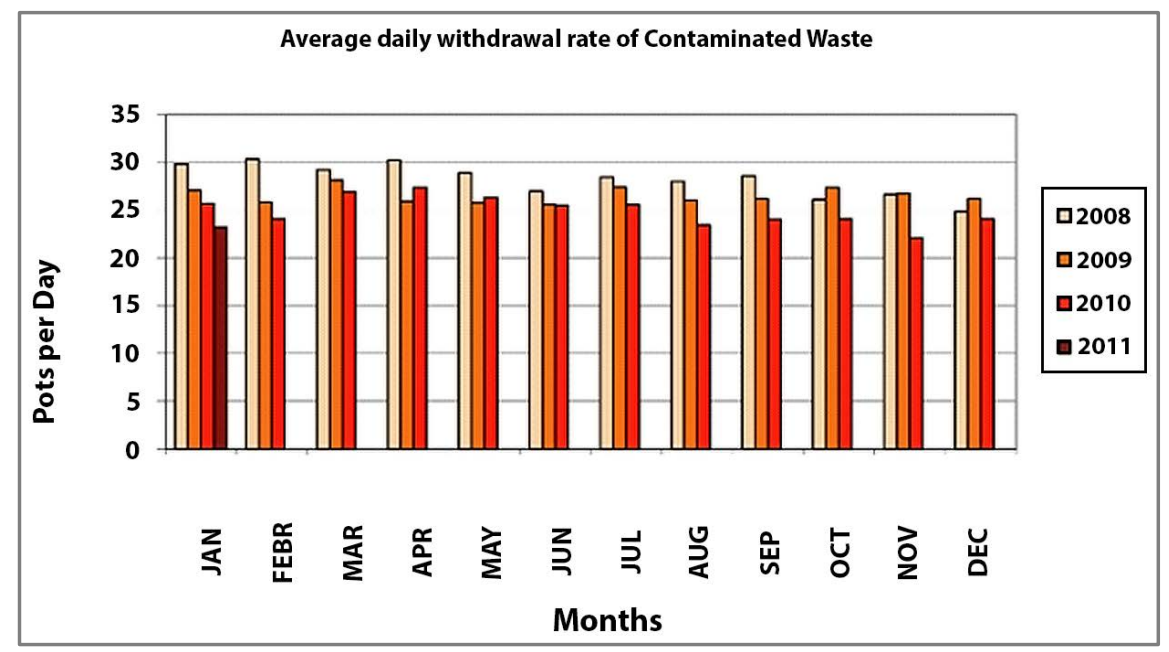

Figure 8. Evolution of the monthly average daily withdrawal rate of contaminated waste, in the period January 2008 to January 20 (pots/day).

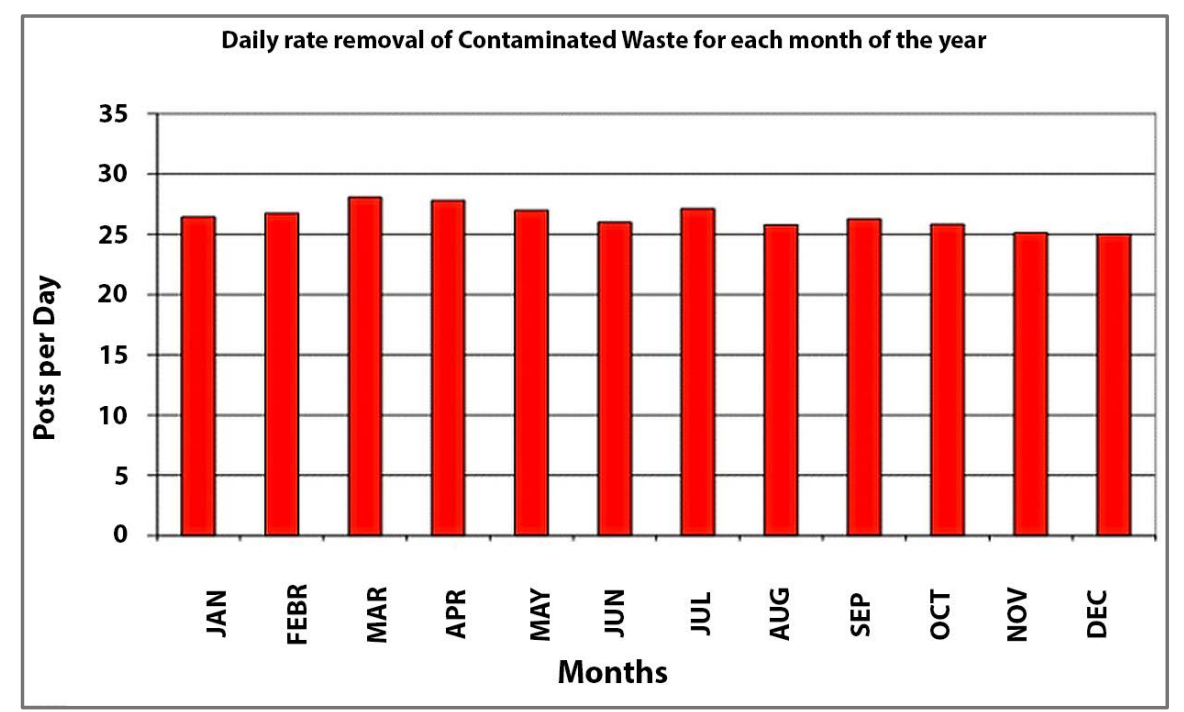

Figure 9. Mean of the daily rate of removal of contaminated waste for each month of the year in the period considered (pots/day). 
contaminated waste that occurs on Sundays, since the teaching area does not work on Sundays and consequently there are no students, which adds to the lower activity of surgery in the CAS.

On the other hand, the highest rate of withdrawal on Sunday is due to the fact that the company contracted on that day does not present any limitations regarding the capacity of withdrawing from pots, thus it is possible to take the pots that could not be carried away due to limitations of space in the previous days.

\section{Conclusions}

In recent years, researchers of waste management focus on waste assessment and recommend many methods and tools for it, such as life cycle assessment [15], impact categorical groups [16], standardized management systems [16], and environmental management accounting [17]. These methods and tools provide the references for Health Care Waste-generation, but their applications in hospital waste management need to be verified in practice and their limitations need to be modified [18].

Currently, the Health Care Waste-generation rate $(\mathrm{kg} / \mathrm{occupied}$ bed/day or $\mathrm{kg} / \mathrm{patient} /$ day) is a popular quantitative indicator to evaluate the performance of Health Care Waste management. However, the generation of Health Care Waste management is affected by many factors. A study in Taiwan found that the types of hospital, reimbursement model, total number of beds, bed occupancy, number of infectious disease beds, and outpatients per day are factors associated with the generation rate [19]. Another study in Greece analyzed the generation rate of 132 health-care facilities. The facilities were grouped into public and private, and into seven subcategories: birth, cancer treatment, general, military, pediatric, psychiatric, and university hospitals. The results showed that there is much variability in the generation rate, even among hospitals of the same category [20]. Therefore, the generation rate is inconvenient for hospital managers to use in practice when they want to set rational goals, especially when they want to compare the performance of different hospitals. The Health Care waste-generation rate is not a homogeneous indicator without considering the differences of the hospital's scale, type, specialization, technical level, quality, and efficiency [21]. People cannot simply use the generation rate to compare performance of Health Care waste management among hospitals. A way to adjust the indicator before comparison is needed.

As part of the diagnosis of Health Care Waste management, a weighing campaign should be carried out to determine the common and contaminated waste generation rates in each of the main services of the CAS. This activity will consist of the systematic execution of waste weights during the diagnostic period and must be carried out by the collectors of the company responsible for cleaning [9]. The procedure defined for performing the weights is discussed below [8]. It is important to clarify that although this procedure arises to evaluate the rates of generation of waste by sector during the diagnosis, it is advisable that the system 
of weighing and registration is carried out on a permanent basis and is incorporated as a routine task to those already assigned to collections [9].

Since it is sought to quantify the waste generated by generation sector, the staff of the cleaning company will be asked not to collect or dispose of waste from different sectors in the same car or tank until they have been weighed. The collector of the corresponding shift must transport the waste directly to the weighing site, without mixing it with waste generated in another sector. This is done with both the common and contaminated waste streams.

The weighing will be carried out in the final storage tank corresponding to the type of waste in question, where a scale must be used to carry out the weighing.

- Common waste

When the collector enters the final storage tank of common waste, they must weigh the waste on the scale, make the corresponding records and then place the bags in the collection sector for later withdrawal by the carrier.

The general procedure consists of weighing each of the bags that were removed from the sector. The collector must record data obtained, for each of the heavy bags, in the registration form, where you must indicate:

- No. of weight

- Date

- Hour

- Generator Service

- Kg weight of the heavy bag

- Volume of heavy bag (estimated)

- Operator

- Signature

The procedure described above should be performed with all bags arriving at the final common waste tank.

- Contaminated waste

When the collector enters the final storage tank of contaminated waste, the waste must be weighed on the scale, the corresponding records must be made and then the bags should be placed in the carts for subsequent removal.

The general procedure consists of weighing each of the bags that were removed from the sector. The collector must record data obtained, for each of the heavy bags, in the registration form, where you must indicate:

- No. of weight

- Date

- Hour

- Generator Service

- Initial volume of waste within the bag of the previous shift (in case the bag already contains waste from another shift)

- Total weight in $\mathrm{kg}$ of the heavy pot

- Volume of waste in the heavy bag

- Operator 


\section{- Signature}

The procedure described above should be performed with all bags arriving from the intermediate tanks to the final tank.

\section{References}

[1] European Waste Catalogue (2001) Decision of the European Commission 2001/118/EC, 16th of January. European Commission, Brussels.

[2] Ananth, A.P., Prashanthini, V. and Visvanathan, C. (2010) Healthcare Waste Management in Asia. Waste Management, 30, 154-161.

https://doi.org/10.1016/j.wasman.2009.07.018

[3] Bdour, A., Altrabsheh, B., Hadadin, N. and Al-Shareif, M. (2007) Assessment of Medical Wastes Management Practise: A Case Study of the Northern Part of Jordan. Waste Management, 27, 746-759. https://doi.org/10.1016/j.wasman.2006.03.004

[4] Decree No 586/009 (2009) Referring to the Regulations Governing the Management of Hospital Waste. Ministry of Public Health, Ministry of Housing, Spatial Planning and Environment, Official Journal.

[5] Bárcena, A., Prado, A., Hopenhayn, M., Beccaria, L., Jaspers, D., Montaño, S. and Malchik, S. (CEPAL) (2010) Chile. Reporte Panorama Social de América Latina, CEPAL, Santiago.

[6] Pruess, Giroult and Rushbrook (1998) Safe Management of Wastes from Health-Care Activities. World Health Organization, 1999. Hong Kong.

[7] Xin, Y. (2015) Comparison of Hospital Medical Waste Generation Rate Based on Diagnosis-Related Groups. Journal of Cleaner Production, 100, 202-207. https://doi.org/10.1016/j.jclepro.2015.03.056

[8] González, E., Rezzano, N., Pitzer, A. and Ramírez, C. (2011) Gestión de residuos sanitarios en el hospital Maciel. Facultad de Ingeniería IMFIA DIA, Uruguay.

[9] CEPAL (2006) Estudio Económico de América Latina y el Caribe 2006-2007. CEPAL, Santiago.

[10] González, E., Rezzano, N., Pitzer, A. and Ramírez, C. (2012) Information Provided in Interview with Personnel Department of Environmental Health of a CAS of the City of Montevideo. UdelaR, Montevideo.

[11] Rezzano, N., Pitzer, A., Ramírez, L. and González, E. (2011) Legislative Framework of Sanitary Waste and Its Application in Uruguay. VII National Congress-AIDIS Uruguayan Section, Montevideo.

[12] González, E., Rezzano, N., Pitzer, A. and Ramírez, C. (2009) Integral Waste Management in a Hospital Center of the City of Montevideo, Phase II. UdelaR, Montevideo.

[13] Ramirez, C. (2013) Design of a Methodological Proposal for the Inter-Institutional Management of Health Care Wastes in Health Care Centers in Montevideo. Master's Thesis, University of the Republic, Montevideo.

[14] Ramírez, A., Pitzer, A., Rezzano, N. and González, E. (2012) Two Experiences of Intrahospital Management of Waste in Montevideo. XXXIII Inter-American Congress of Sanitary and Environmental Engineering. AIDIS, Montevideo, 5.

[15] Bersimisa, Sotirios, Georgakellosb and Dimitrios (2013) A Probabilistic Framework for the Evaluation of Products' Environmental Performance Using Life Cycle Approach and Principal Component Analysis. Journal of Cleaner Production, 42, 103-105. https://doi.org/10.1016/j.jclepro.2012.10.038 
[16] Carvalhoa, A., Mimosob, A.F., Mendesb, A.N. and Matosb, H.A. (2014) From a Literature Review to a Framework for Environmental Process Impact Assessment Index. Journal of Cleaner Production, 64, 36-62. https://doi.org/10.1016/j.jclepro.2013.08.010

[17] Simona, A., Bernardob, M., Karapetrovicc, S. and Casadesúsa, M. (2011) Integration of Standardized Environmental and Quality Management Systems Audits. Journal of Cleaner Production, 19, 2057-2065. https://doi.org/10.1016/j.jclepro.2011.06.028

[18] Papaspyropoulosa, K.G., Blioumisa, V., Christodouloua, A.S., Birtsasb, P.K. and Skordasc, K.E. (2012) Challenges in Implementing Environmental Management Accounting Tools: The Case of a Nonprofit Forestry Organization. Journal of Cleaner Production, 29-30, 132-143. https://doi.org/10.1016/j.jclepro.2012.02.004

[19] Eagan, P.D. and Joeres, E. (1997) Development of a Facility-Based Environmental Performance Indicator Related to Sustainable Development. Journal of Cleaner Production, 5, 269-278. https://doi.org/10.1016/S0959-6526(97)00044-9

[20] Cheng, Y.W., Sung, F.C., Yang, Y., Lo, Y.H., Chung, Y.T. and Li, K.C. (2009) Medical Waste.

[21] Komilis, D., Fouki, A. and Papadopoulos, D. (2012) Hazardous Medical Waste Generation Rates of Different Categories of Health-Care Facilities. Waste Management, 32, 1434-1441. https://doi.org/10.1016/j.wasman.2012.02.015 